\title{
Impacts of Air-Fuel Stratification in ACl Combustion on Particulate Matter and Gaseous Emissions
}

\author{
Melanie Moses-DeBusk ${ }^{1}$ (D) S Scott J. Curran ${ }^{1} \cdot$ Samuel A. Lewis $\mathrm{Sr}^{1} \cdot$ R. Maggie Connatser ${ }^{1} \cdot$ John M. E. Storey $^{1}$
}

Received: 7 February 2019 /Revised: 8 April 2019 / Accepted: 25 April 2019 / Published online: 11 May 2019

(C) The Author(s) 2019

\begin{abstract}
Since multi-mode engine combustion strategies are being investigated as a pathway to increased vehicle fuel efficiency, a better understanding of particulate matter formation during the advanced compression ignition (ACI) modes and the resulting PM properties are of growing importance for mitigating PM emissions and/or developing emissions control strategies. ACI combustion strategies have demonstrated extremely low engine-out soot while achieving high break thermal efficiencies. However, USregulated emissions for particulate matter (PM) are on a mass basis, which can consist of ash, soot or elemental carbon (EC), and organic carbon (OC). The composition of PM mass from ACI combustion ranges from nearly $100 \%$ OC to a mix of EC and OC particulates as the extent of fuel stratification increases. How the mass, compositions, and morphology of PM changes as fuel stratifies within the combustion chamber and what this can tell us about PM formation are presented through multi-cylinder, metal engine experiments. Using ACI modes ranging from homogeneous to highly stratified approaches, this study aimed to advance the understanding of how air-fuel stratification and fuel properties impact PM emissions formation; advanced gaseous and solid emission characterizations are also given. This study is part of a collaborative multi-lab initiative at the US Department of Energy that aims to simultaneously transform both transportation fuels and vehicles in order to maximize performance and energy efficiency, minimize environmental impact, and accelerate widespread adoption of innovative combustion strategies by providing the underlying science for this initiative.
\end{abstract}

Keywords Advanced compression ignition · Particulate matter · Low-temperature combustion · EC/OC speciation · Particle sizing $\cdot$ HCCI

This manuscript has been authored by UT-Battelle, LLC under Contract No. DE-AC05-00OR22725 with the US Department of Energy. The US Government retains and the publisher, by accepting the article for publication, acknowledges that the US Government retains a non-exclusive, paid-up, irrevocable, world-wide license to publish or reproduce the published form of this manuscript, or allow others to do so, for US Government purposes. The Department of Energy will provide public access to these results of federally sponsored research in accordance with the DOE Public Access Plan (http://energy.gov/downloads/doe-publicaccess-plan).

Melanie Moses-DeBusk

mosesmj@ornl.gov

John M. E. Storey

storeyjm@ornl.gov

1 National Transportation Research Center, Energy and Transportation Science Division, Oak Ridge National Laboratory, Oak

Ridge, TN 37830, USA

\section{Introduction}

The US Department of Energy's (DOE) Co-Optimization of Fuels and Engines (Co-Optima) initiative [1] is working to advance the underlying science needed to develop fuel and engine technologies that will work in tandem to achieve significant efficiency gains. As part of this line of investigation, understanding the emissions from advanced compression ignition modes (ACI), which may be part of a light-duty multimode strategy or for either multi-mode or full-time medium- $/$ heavy-duty next-generation engines, are of importance. There is a range of ACI modes under investigation that have been shown experimentally to offer high brake thermal efficiency (BTE) with low engine-out NOx and soot using diesel-like fuels and gasoline-like fuels along with dual-fuel approaches. Using gasoline-like fuels for ACI modes offers higher volatility, lower boiling ranges, and a higher resistance to autoignition than diesel-like fuels. ACI modes using 
gasoline-like fuels can include both low-temperature combustion modes as well as ACI modes that may not be classically defined as low-temperature combustion but still show advantages in improving efficiency or lowering engine-out NOx and/or soot emissions compared to conventional diesel combustion (CDC) run with market diesel-like fuels (i.e., high boiling range, high cetane number, and significant viscosity).

Recent work from our lab, reported by Dempsey et al. [2], classified ACI combustion modes using gasoline-like fuels based on their level of in-cylinder air-fuel stratification. In that paper, the classification of ACI strategies with gasoline-like fuels was split into the following classifications: homogeneous (HCCI), partial fuel stratification (PFS), moderate fuel stratification (MFS), and heavy fuel stratification (HFS). Dempsey's work used the injection centroid metric to determine which category a combustion mode fell into since many of the modes described used multiple injections. Both HCCI and PFS have similar centroids of injection, $\sim 300$ crank angle degree (CAD) to 120 CAD before top dead center (BTDC). While the HCCI strategy has all the fuel premixed, the PFS strategy has most of the fuel premixed but also includes a later direct injection (DI) event during the compression stroke to set-up partial stratification of the charge. They each have a large separation between the injection event(s) and start of combustion and can therefore be considered kinetically controlled combustion modes. The other extreme of the incylinder air-fuel stratification is HFS, in which all the DI events occur near TDC and more closely resembles conventional diesel combustion strategies with a centroid of injection of about $40 \mathrm{CAD}$ to $0 \mathrm{CAD}$ BTDC. Figure 1 shows the bookends of the ACI spectrum, which are of interest to the current study. Figure 1 represents how premixed the air-fuel charge was at start of combustion, which is important to the number of localized regions that may be sufficiently fuel-rich to support the formation of soot. [3]

Because ACI combustion approaches typically have global fuel mixtures that are very lean, soot is not expected to form under conventional pathways. Previous research has examined the PM for single- and dual-fuel ACI modes with differing levels of stratification have largely used smokemeters (FSN) or particle sizing equipment such as a scanning mobility particle sizer (SMPS) to measure PM [4-9] although some studies included gravimetric filter PM measurement $[10,11]$. The study by Dempsey et al. examined mixture preparation in GCI operation and found no measurable smoke $(\mathrm{FSN}<0.00)$ at the operating points [2]. The study by Ciatti et al. [6] had large variances in smoke number $(<0.2<$ FSN $<4)$ and no other PM measurements. Sellnau et al. published a series of studies with their single and multicylinder engines that used a stratified approach to ACI with commercial gasoline ( $87 \mathrm{AKI} 10 \%$ ethanol) and showed soot numbers well below $0.1[4,5]$. Lucachick et al. [12] measured particle size distributions from an engine operating in a dual-fuel ACI mode with gasoline and diesel and found that the particles were largely volatile. Another study of an HCCI engine fueled with ethanol determined that the particle size distributions largely disappeared when evaporated at $100^{\circ} \mathrm{C}$, indicating they were primarily volatile particles [7]. Overall, the aforementioned studies showed extremely low smoke numbers and particle number concentrations for ACI PM. In addition to the real-time measurements, a few studies found that, even at low FSN and particle number emissions, the ACI engine could emit significant mass as collected on sampling filter [10, 11]. Because PM mass emissions are regulated, understanding what contributes to the mass on the filter is critical to controlling the PM from ACI combustion modes. Extensive coverage of this was reported by Storey et al. [11] and concluded that the PM from their ACI engine was primarily organic carbon (OC) that had collected on the filter. The PM characterization of ACI appears to illustrate that techniques developed for diesel engines such as FSN determination and photoacoustic soot determination may not be applicable due to the different formation pathways for ACI PM.
Fig. 1 Bookends of advanced compression ignition combustion strategies with gasoline-like fuels and diesel-like fuel

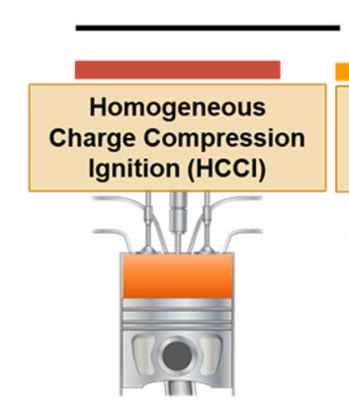

- Air-fuel fully premixed

- Kinetically controlled
Increasing Air Fuel Stratification

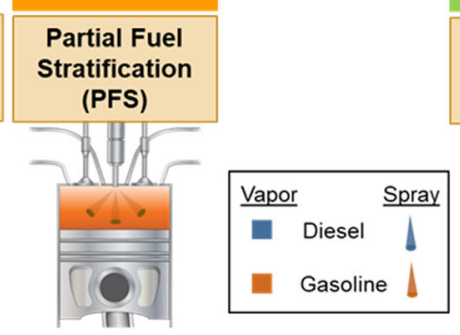

- Majority fuel premixed (50-95\%)

- Injection midway through compression stroke

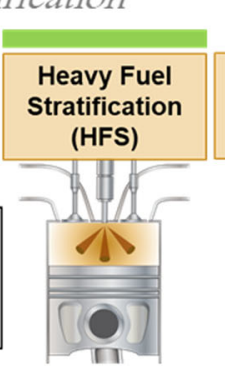

- Single or multiple injection events

- All injections near TDC compression
Conventional Diesel Combustion (CDC)

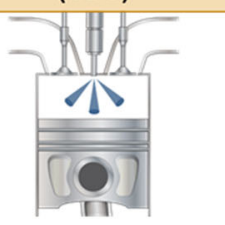

- Modern diesel injection (main + pilot)

- All injections near TDC compression 
This current work investigated the bookends of ACI to understand the impacts that occur from increasing the amount of air-fuel stratification when using gasoline-like fuels. Two different gasoline-like fuels were explored, a lower octane, higher reactivity fuel (70 RON), and a US pump grade RON fuel (87 RON) that did not contain ethanol. The fuels for these exploratory experiments were chosen to provide preliminary insights for future studies on how fuel properties impact ACI PM formation by starting with mid and low RON gasolinelike fuels. Determining the characteristics of the emissions from ACI combustion modes is an important first step in enabling the use of these high-efficiency engines. Furthermore, for the co-optimization of fuels and engines that provide better efficiency, a more complete understanding of fuel property effects and combustion mode effects is needed. This study is a first step in understanding both of these effects on PM and gaseous emissions.

\section{Experimental}

The current study examines the fuel and combustion stratification effects on the formation of ACI PM. The experimental results presented here are from a multi-cylinder light-duty diesel engine, modified to operate in the ACI combustion mode, and using gasoline-like fuels. The following sections describe the engine and the methodology used for investigating and characterizing gaseous hydrocarbons (HCs) and PM from ACI combustion.

\subsection{Engine}

The engine used for this study was a modified 2007 GM DI $1.9 \mathrm{~L}$ diesel engine. This modern, light-duty diesel engine was equipped with the original high-pressure common-rail injection system, high-pressure exhaust gas recirculation (EGR), variable geometry turbocharger, and variable swirl actuation. The stock pistons were used, and Table 1 gives the engine geometry and specifications. The fuel is direct injected using the original common-rail diesel fuel system with centrally mounted injectors that were designed for conventional diesel combustion (7-hole injector with an included spray angle of $148^{\circ}$ ). The fuel supply and return were replaced with an inhouse fuel delivery, conditioning, and measurement system. Additional cooling for the fuel supply and return streams was used as the original equipment fuel injection system was not designed around DI of gasoline boiling range fuels. Further information about the use of gasoline-like fuels with additional fuel conditioning can be found in the study by Dempsey et al. [2]

A full-pass control system allowing simultaneous control of each DI injector, as well as all other relevant engine parameters, such as rail pressure, boost, and swirl control, was used
Table 1 Specifications for the 2007 GM 1.9 L multi-cylinder diesel engine

\begin{tabular}{ll}
\hline Number of cylinders & 4 \\
Bore $[\mathrm{mm}]$ & 82.0 \\
Stroke $[\mathrm{mm}]$ & 90.4 \\
Displacement [L] & 1.91 \\
Compression ratio [-] & 16.5 \\
IVO $\left[{ }^{\circ} \mathrm{CA}\right.$ aTDC] & 344 \\
IVC $\left[{ }^{\circ} \mathrm{CA}\right.$ aTDC] & -132 \\
$\mathrm{EVO}\left[{ }^{\circ} \mathrm{CA}\right.$ aTDC] & 116 \\
EVC $\left[{ }^{\circ} \mathrm{CA}\right.$ aTDC] & -340 \\
Rated power $[\mathrm{kW}]$ & 110 \\
Rated torque $[\mathrm{Nm}]$ & 315 \\
\hline
\end{tabular}

aTDC after top dead center, $C A$ crank angle, $E V C$ exhaust valve closing, $E V O$ exhaust valve opening, IVC intake valve closing, $I V O$ intake valve opening.

in place of the original engine control unit. Engine torque was measured using an AC motoring/absorbing dynamometer. The DI fuel flow rate was measured with a Micro Motion Coriolis fuel meter, while the intake air flow rate was measured using a laminar flow element.

In-cylinder pressure data, for all cylinders, were acquired with Kistler model 6125 6058A pressure transducers, which were flush-mounted via the machined glow plug ports in the cylinder head. Synchronous high-speed data (in-cylinder pressure, injector current probes, etc.) were recorded for 300 consecutive cycles for all four cylinders, and low-frequency data (flow rates, temperatures, pressures, emissions, etc.) were recorded for $180 \mathrm{~s}$ at $2 \mathrm{~Hz}$. Further information about the engine configuration and measurement set-up have been previously reported [13].

\subsection{Gaseous Emission Sampling}

Criteria emissions including $\mathrm{CO}, \mathrm{CO}_{2}, \mathrm{NOx}, \mathrm{HC}$, and $\mathrm{O}_{2}$ were measured with standard gaseous emission analyzers sourced from California Analytical Instruments. A heated flame ionization detector (FID) was used to measure total unburned hydrocarbons (THC). The THC emissions are reported on a $\mathrm{C}_{1}$-basis. A heated chemiluminescence analyzer (CLD) was used to measure total $\mathrm{NOx}$ emissions $\left(\mathrm{NO}+\mathrm{NO}_{2}\right)$. Both $\mathrm{CO}$ and $\mathrm{CO}_{2}$ were measured with non-dispersive infrared (NDIR) instruments: $\mathrm{CO}$ was measured in the exhaust with a dedicated instrument with simultaneous high and low ranges, and $\mathrm{CO}_{2}$ was measured in both the exhaust and intake with separate instruments. Intake and exhaust $\mathrm{O}_{2}$ were measured with separate instruments, both using a paramagnetic detector (PMD). Intake and exhaust $\mathrm{CO}_{2}$ concentrations were measured to calculate the EGR rate. The exhaust sample stream was maintained at $190{ }^{\circ} \mathrm{C}$ through heated filters and heated lines. Water 
was condensed out of the exhaust stream before being sampled by the PMD and NDIR instruments.

An FTIR (MKS Multigas 2030HS) was also used for exhaust sampling, with the sampling port located after the turbocharger. Raw exhaust was sampled via a heated line $\left(191{ }^{\circ} \mathrm{C}\right)$ and filtered through a heated filter. FTIR measurements included a range of species, including: $\mathrm{NO}, \mathrm{NO}_{2}, \mathrm{CO}$, $\mathrm{CO}_{2}$.

\subsection{Sampling for Speciated HC and PM}

The engine exhaust was also characterized for carbonylcontaining compounds, as well as PM mass, chemistry, number, and size. For the carbonyls and filter samples, dilute exhaust samples were collected with a micro-dilution system shown in the schematic of the experimental set-up shown in Fig. 2. Gaseous aldehydes and ketones were collected using dinitrophenyl hydrazine (DNPH)-coated solid-phase extraction cartridges (Waters Corp., Milford, MA, USA, Part no. WAT037500). The sample flow rate was $1.0 \mathrm{l} / \mathrm{min}$. A minimum of two DNPH cartridges were collected for each fuel type. Directly following sample collection, DNPH derivatives were solvent-extracted with acetonitrile. Determination of aldehyde and ketone concentrations was performed by a Hewlett-Packard 1100 high-performance liquid chromatograph (HPLC) using a Waters X-Bridge phenyl column (Part no. 186003328 , Milford, MA, USA) with ultraviolet adsorption detection. Elution times were validated when eluent of the HPLC unit was transferred directly to a Bruker Daltonics ${ }^{\circledR}$ Esquire mass spectrometer where the hydrazone derivatives were positively identified using electrospray with negative ionization mass spectrometry (ESI-MS). The dilution ratio was $\sim 9$ and the dilute exhaust temperature was maintained at $\sim 47{ }^{\circ} \mathrm{C}$. For collection and analysis of elemental carbon/ organic carbon (EC/OC) samples, a single sample was pulled off the micro-dilution system before splitting into two parallel sampling streams. On one sample stream, the diluted exhaust was pulled through a quartz fiber filter $(\mathrm{QF}$, pre-fired Pall 2500 QAOT-UP). On the second stream, the diluted exhaust was pulled through two different filters in series; a polytetrafluoroethylene (PTFE) membrane filter (TF, Whatman, $\mathrm{PM}_{2.5}$ PTFE membrane filter) was the primary filter, followed by a secondary QF. The TF was weighed before and after for PM mass. Both the primary and secondary QFs were submitted to Sun Laboratory Inc. for OC and EC determination by the NIOSH method [14]; the absorbed organics on the secondary QF can be subtracted from the organics found on the primary $\mathrm{QF}$ to correct for known filter adsorption artifacts of $\mathrm{HC}$ [15]. In addition to the two QF filters used for $\mathrm{EC} / \mathrm{OC}$ samples, a third QF was collected for later chemical speciation of the PM. [16]

In addition to filter measurements, PM size and number measurements were made on the exhaust after a separate exhaust slip-stream was sent to a heated two-stage dilution system which included a $350{ }^{\circ} \mathrm{C}$ evaporator tube (shown in Fig. 2) using an Engine Exhaust Particle Sizer (EEPS model 3090, TSI, Inc.). The EEPS measures particle size distributions between 6 and $560 \mathrm{~nm}$, reporting them in size bins, and provides a total particle number concentration. The two-stage dilution system is based on an ejector pump design, similar to that of the European Particle Measurement Program (PMP) [17]. This design consists of a micro-tunnel dilution system paired with an evaporator tube followed by a second micro-tunnel dilution. The first stage dilutes $191^{\circ} \mathrm{C}$ exhaust with air that has

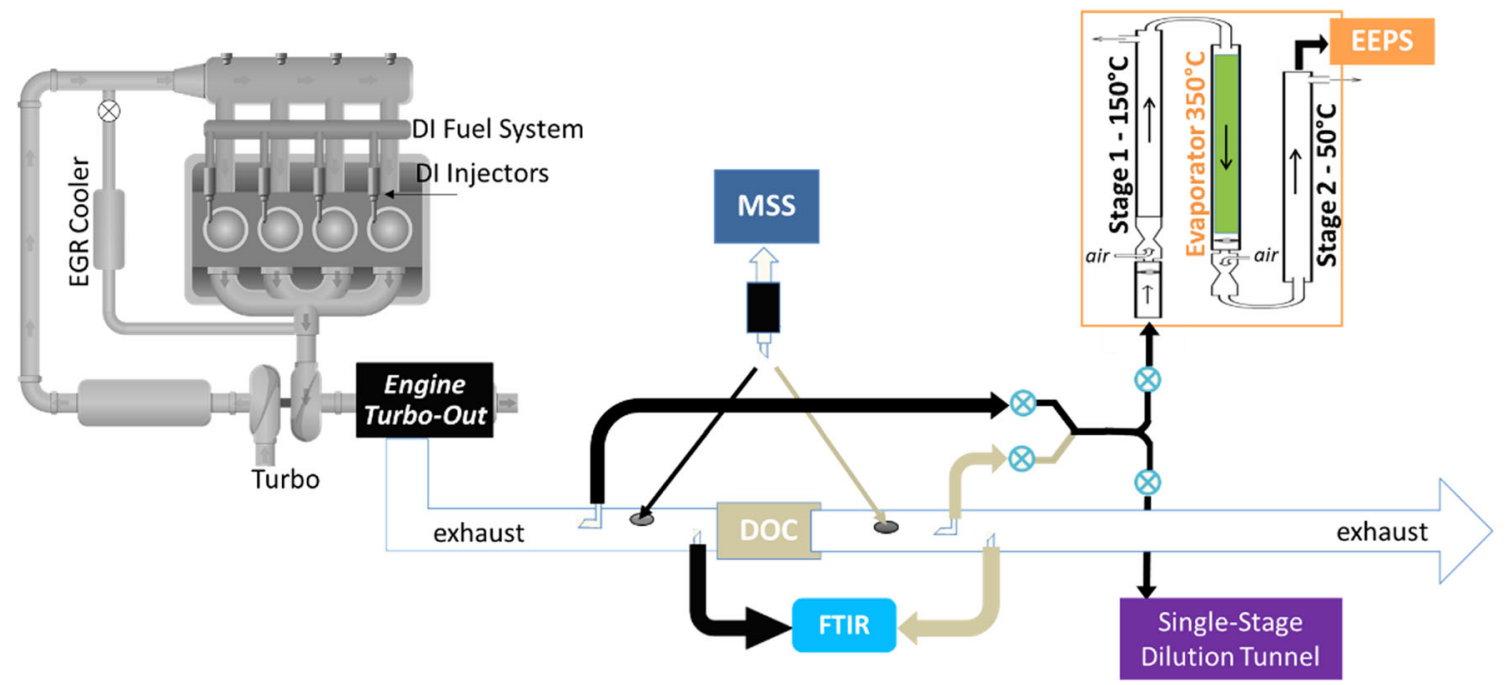

Fig. 2 Sampling schematic. The Microsoot Sensor (MSS) and FTIR were manually switched between the Engine-out and DOC-out positions. The lines and the manifold leading to the dilution tunnels were heat traced and kept at $190^{\circ} \mathrm{C}$. The single-stage dilution tunnel was maintained at $47^{\circ} \mathrm{C}$.
Filter samples for OC/EC as well as PM speciation and DNPH cartridges for aldehydes and ketones were sampled from the single-stage tunnel. The dual stage tunnel was used to measure PM size and number with the Engine Exhaust Particle Sizer (EEPS) 
been heated to $150{ }^{\circ} \mathrm{C}$; the dilute exhaust is then sent to the evaporator tube, maintained at $350{ }^{\circ} \mathrm{C}$, and then undergoes a second stage dilution after which the doubly diluted exhaust is maintained at $50{ }^{\circ} \mathrm{C}$. The overall dilution ratio was $\sim 60$.

In addition to filter sampling, a photoacoustic sensor (MSS, AVL 483) was used to measure the soot PM concentration in the exhaust and used the MSS's own sample conditioning system to dilute and condition the exhaust sample.

\subsection{Fuels}

Two fuels were used in this study, which had different Research Octane Numbers (RON), 87 RON and 70 RON. The 87 RON fuel, which had an anti-knock index (AKI) of 85 , was a blendstock for oxygenated blending (BOB) but was used without further blending. This fuel was sourced from Gage products and had previously been used as part of a larger DOE Co-Optima fuels study [18]. The 70 RON fuel was an even lower RON, gasoline-like fuel which contained a lower aromatic content, almost no olefins, and higher saturate content than the 87 RON fuel and was sourced from Haltermann as product-TR1937 - 70 RON BASE FUEL. Table 2 contains the fuel properties for both fuels, more information about the BOB can be found in [18]. Of note is the higher aromatics content and T90 of the 87 RON fuel. For these experiments, a commercial lubricity improver (Infinium R655) was used at $300 \mathrm{ppm}$ to protect the high-pressure fuel pump. Details regarding the use of this lubricity improver with volatile fuels and this DI fuel system have been previously reported [2].

\subsection{Engine Operating Points}

For the engine experiments, an engine speed of $2000 \mathrm{rpm}$ and a load of 5 bar BMEP for the 87 RON fuel points and 4 bar BMEP for the 70 RON fuel points was used to evaluate and compare ACI operation. While higher loads are achievable with HFS, the goal was to span the range of stratification and maintain a window of combustion timing at fixed speed over the two load points. These experiments focused on the bookends of the stratification spectrum discussed in the

Table 2 Selected fuel properties

\begin{tabular}{lll}
\hline & $70 \mathrm{RON}$ & $87 \mathrm{RON}$ \\
\hline Reid vapor pressure (RVP, psi) & 7.0 & 11.7 \\
Distillation T50 (F) & 210.5 & 214 \\
Distillation T90 (F) & 271.2 & 285 \\
Aromatics (vol\%) & $15.5 \%$ & $19.4 \%$ \\
Olefins (vol\%) & $0.3 \%$ & $3.7 \%$ \\
Saturates (vol\%) & $84.2 \%$ & $75.7 \%$ \\
MON & 68 & 83 \\
\hline
\end{tabular}

introduction. For discussion of PM formation, a distinction of these bookends that is worth noting is the differences in time remaining, after the end of fuel injection, for air-fuel mixing before ignition, as shown in Fig. 3. The extended mixing time enables local areas within the cylinder to stay well mixed and lean, so as to avoid the formation of soot [3].

The cylinder pressure and heat release rate (HRR) traces for the engine operating points are shown in Fig. 4, along with additional information regarding combustion phasing (CA50), injection centroid on the plots. The HCCI ( $87 \mathrm{RON}$ and 70 RON fuel) and PFS points (70 RON fuel only) shown in Fig. $4 \mathrm{a}-\mathrm{c}$ had centroids of injection quite early (>180 BTDC) leading to more premixing. These injection timings resulted in what are described as kinetically controlled combustion regimes that had early combustion phasing close to TDC with short combustion durations typical of these modes. The second set of points, Fig. 4d-f, with injection timings and centroids (< $20^{\circ} \mathrm{BTDC}$ ), are closer to $\mathrm{CDC}$ regimes and are more stratified which resulted in a more retarded combustion phasing. Finally, at the highest fuel stratification mode for the 70 RON fuel, an EGR sweep was done $(25 \%, 15 \%$, and $0 \%)$ Fig. $4 \mathrm{f}-\mathrm{h}$. The injection timing for the HFS-EGR sweep got closer and closer to TDC, from $9.9^{\circ}$ to $5.6^{\circ} \mathrm{BTDC}$ as less EGR was used.

\section{Results and Discussion}

The impact of fuel properties within combustion modes, as well as the effect of combustion strategies, is discussed in the following section.

\subsection{Criteria Pollutant Emissions}

The criteria pollutant emissions in the engine-out exhaust are shown in Table 3. The NOx and CO emissions were measured with an FTIR, and THC emissions were measured with a FID. The HCCI and PFS points had very low NOx emissions, with concurrent high $\mathrm{CO}$ and $\mathrm{THC}$, as expected for kinetically controlled combustion. These combustion modes can be classified as low-temperature combustion as they resulted in extremely low engine-out NOx and low soot as measured by the MSS [2]. Emission trends for the HFS points were less clear. The 87 RON fuel saw a decrease in the NOx and CO emissions as stratification increased between the two HFS points. For the 70 RON fuel, the NOx increased for the EGR sweep as EGR dropped from 25\% to 0\%. Dropping the amount of EGR increased stratification demonstrating the need for high EGR rates to achieve conventional LTC operation.

\subsection{Aldehyde Emissions}

The speciated aldehydes were measured with DNPH cartridges from the dilute exhaust and are shown in Fig. 5. 
Fig. 3 Injection schedule for ACI strategies investigated (HCCI, PFS and HFS) with cylinder pressure and HRR shown to illustrate relationship between end of injection and start of combustion

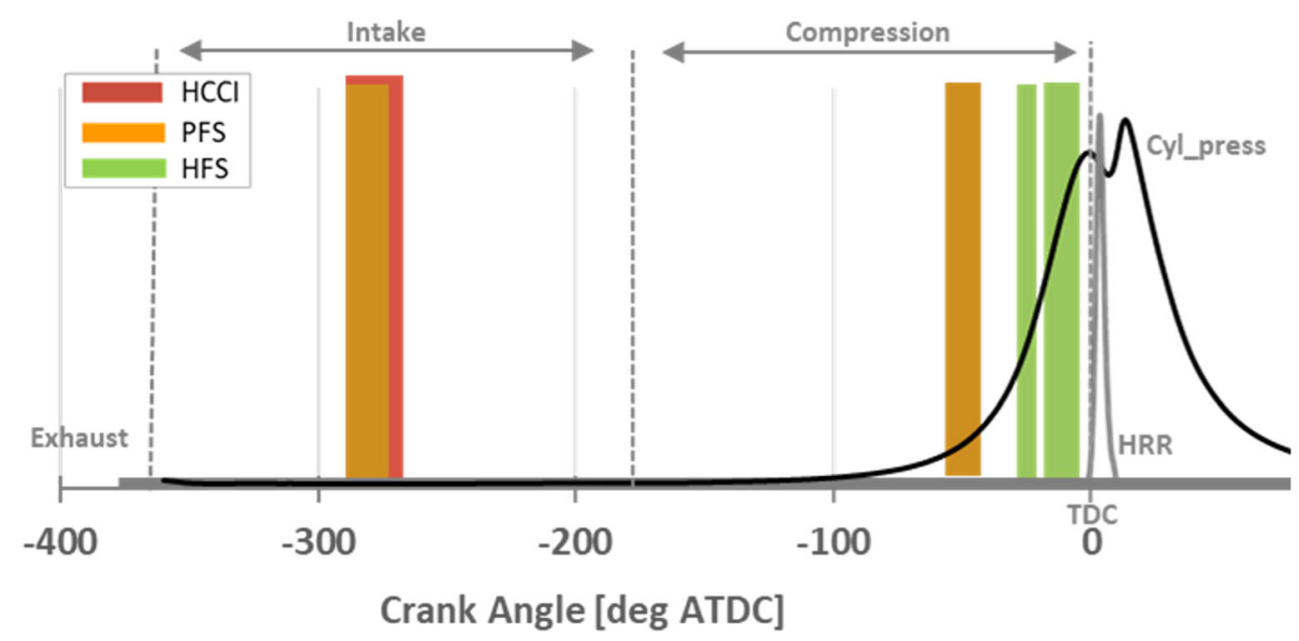

The aldehydes produced at these combustion points were dominated by formaldehyde, for both fuels, and reached emissions rates from $25 \%$ to $60 \%$ of the THC emission rates measured by the FID, see Fig. 5 and Table 4. It is important to note that formaldehyde is detected by the FID significantly less sensitively, so that fraction of the aldehyde emissions will be underrepresented in Fig. 5b THC rate and must be considered along with the THC rate as part of the calculation when determining non- methane organic gases (NMOG). The longer-chain aldehydes can be measured by an FID but at varying response levels. High levels of formaldehyde in kinetically controlled ACI combustion studies have been previously reported $[19,20]$.

The higher aldehyde and THC emission rates seen for the HCCI and PFS modes, compared to the HFS modes, may be related to the slightly lower combustion temperatures common for kinetically controlled combustion. These temperatures
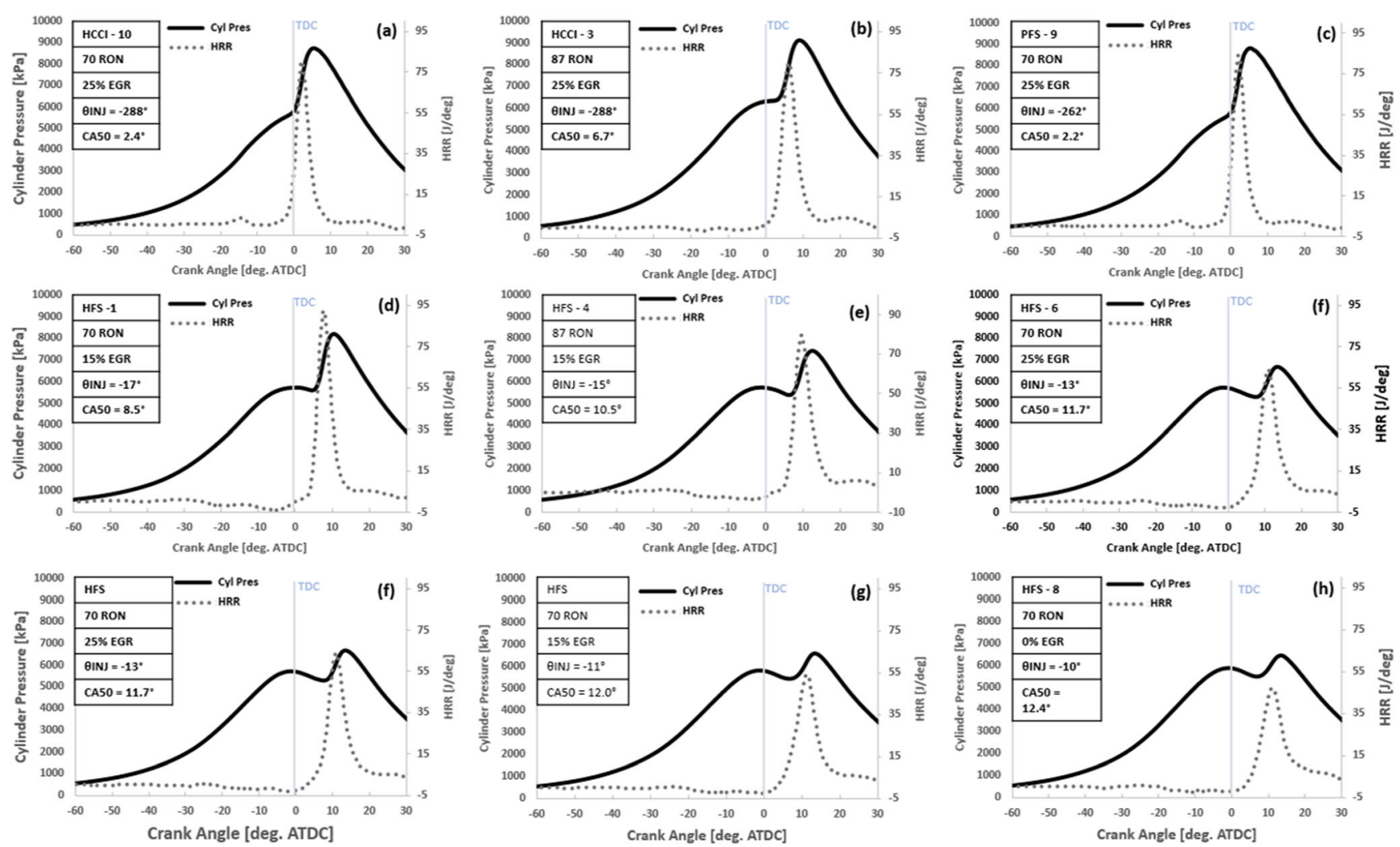

Fig. 4 Cylinder pressure and HRR are shown for the ACI engine operating points studied and are organized: top row-kinetically controlled (HCCI and PFS); middle row-HFS; bottom row-HFS-EGR sweep. Abbreviations - centroid of injection $\left(\theta_{\mathrm{INJ}}\right)$, CA50, combustion

phasing. The 70 RON-HFS at $25 \%$ EGR in plot (f) is displayed twice for comparison purposes with 87 RON-HFS points (middle row) and as part of the 70 RON EGR sweep (bottom row) 
Table 3 Criteria pollutant emissions from the ACI engine conditions sorted by centroid of injection. Concentrations used to calculate emissions rate were measured by the FTIR and FID

\begin{tabular}{|c|c|c|c|c|c|}
\hline & \multirow[t]{2}{*}{ Centroid of Inj $\left(^{\circ}\right)$} & \multirow[t]{2}{*}{$\operatorname{EGR}(\%)$} & \multicolumn{3}{|c|}{$\mathrm{g} /(\mathrm{bhp} * \mathrm{~h}(\mathrm{ppm})$} \\
\hline & & & $N O x$ & THC & $\mathrm{CO}$ \\
\hline HCCI (70 RON) & 288 & 25 & $0.02(2)$ & $10.5(3695)$ & $13.5(2187)$ \\
\hline HCCI (87 RON) & 288 & 15 & $0.02(3)$ & $13.3(4418)$ & $16.6(2545)$ \\
\hline PFS (70 RON) & 262 & 25 & $0.04(5)$ & $10.9(3880)$ & $15.8(2584)$ \\
\hline HFS 1 (87 RON) & 17 & 15 & $4.2(566)$ & $2.1(728)$ & $9.1(1457)$ \\
\hline HFS 2 (87 RON) & 15 & 15 & $2.9(420)$ & $1.7(620)$ & $9.1(1569)$ \\
\hline HFS 1 (70 RON) & 13 & 25 & $1.5(175)$ & $2.2(721)$ & $8.5(1303)$ \\
\hline HFS 2 (70 RON) & 11 & 15 & $2.3(287)$ & $1.7(560)$ & $3.8(595)$ \\
\hline HFS 3 (70 RON) & 10 & 0 & $3.5(363)$ & $1.9(507)$ & $2.0(333)$ \\
\hline
\end{tabular}

might explain the increase in both unburned, partially oxidized, and cracking product $\mathrm{HCs}$, likely fuel $\mathrm{HCs}$, evident in the high THC and aldehyde emissions measured. The $87 \mathrm{RON}$ fuel had lower aldehyde formation, especially formaldehyde, but higher THC in the HCCI mode than the 70 RON fuel. Since formaldehyde formation is more likely to proceed through oxidation of the partial cracking products of saturated HCs, rather than via hydroxyl radical attack of unburned or partially oxidized aromatic or olefinic $\mathrm{HC}$ fuel constituents, the difference in HCCI emissions between the two fuels may be related to the fuel composition. To that point, the $70 \mathrm{RON}$ fuel had a higher
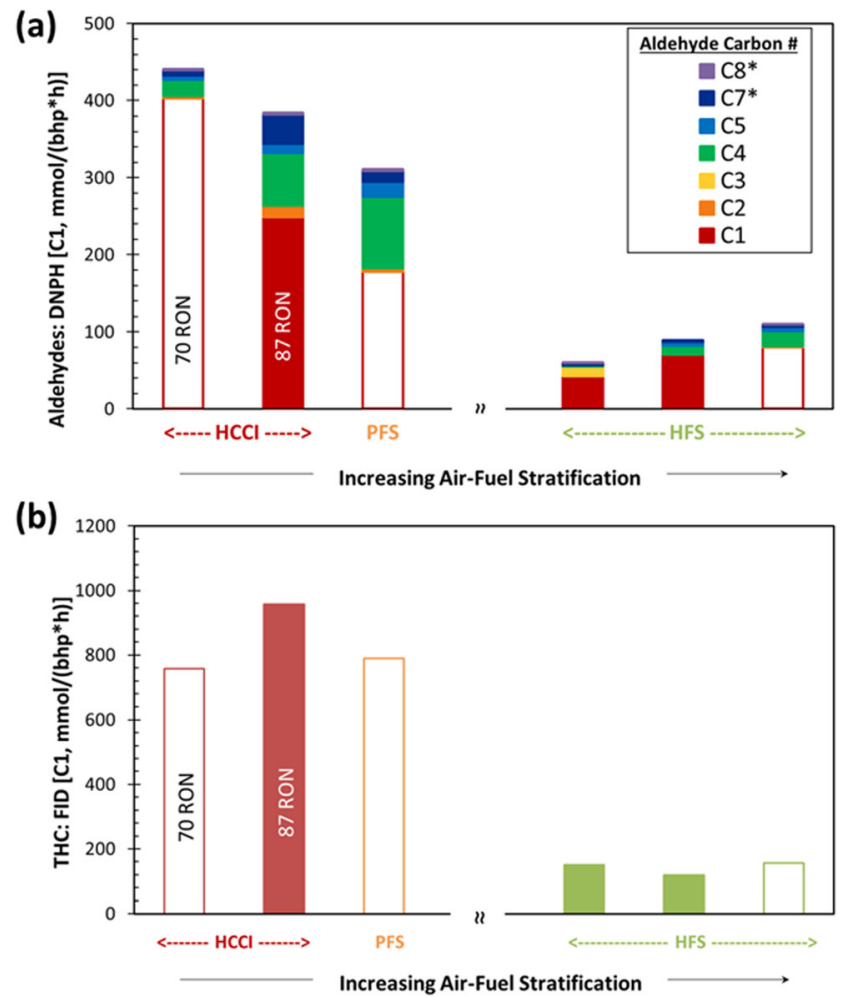

Fig. 5 Aldehyde (a) and THC (b) emission rates during kinetically controlled and HFS modes. For purposes of comparison, the units are normalized to moles of $\mathrm{C}_{1}$ instead of mass. The 70 RON fuels points are distinguished by the unshaded bars for formaldehyde in (a) and $\mathrm{THC}$ in (b). *The $\mathrm{C} 7$ and $\mathrm{C} 8$ aldehydes in a represent aromatic aldehydes saturated HC fraction than the 87 RON fuel, which instead had a higher fraction of aromatics (Table 2). Correspondingly, the higher THC emissions of the less reactive, $87 \mathrm{RON}$ fuel, relates to the fuel's lower saturated $\mathrm{HC}$ and increased aromatic fuel $\mathrm{HCs}$. This suggests that the fuel $\mathrm{HC}$ composition contributed to the aldehyde-to-THC emissions trade-off. This fuel effect is further supported by the 87 RON fuel's production, especially in the HCCI mode, of higher benzaldehyde emissions (C7 aldehyde, Fig. 5a), which is a partial oxidation product of toluene, typically the largest aromatic in gasoline.

While a significant drop in total aldehydes and THC was seen for the HFS modes compared to the kinetically controlled modes, regardless of fuel, a larger drop in THC than aldehyde emissions was typically seen (Table 4). Like the kinetically control modes, formaldehyde was still the dominant aldehyde for all of the HFS modes. Comparison of the 87 RON-HFS 1 point to the 70 RON-HFS 1 point showed a similar fuel effect on formaldehyde production as that discussed for the kinetically controlled modes. However, an increase in formaldehyde production combined with a drop in the THC emissions rates was seen between the two 87 RON-HFS points, suggesting other variables may play a more prominent role in impacting these emissions in the HFS modes.

\subsection{PM Mass and Organic Carbon/Elemental Carbon Emissions}

Filter samples of exhaust PM were collected at each condition and analyzed for mass and carbon compositions, Table 5. Figure 6 shows the total PM mass collected and mass quantified from EC/OC data analyses using the NIOSH method for both the premixed and stratified modes. The NIOSH method is a thermo-optical method to identify PM mass as either organic carbon (OC) or elemental carbon (EC) [14]. The $\mathrm{PM}_{2.5}$ PTFE membrane filter used for EPA regulated total PM mass measurements was also collected [21] and compared to the total carbon (TC) measured by the NIOSH method. Because of the varying EGR rates, and thus exhaust flow rates, the PM 
Table 4 Comparison of THC (FID) and aldehyde (DNPH) emission rates on $\mathrm{C}_{1}, \mathrm{mmol}$ basis

\begin{tabular}{llllll}
\hline & FID (THC) & \multicolumn{2}{l}{ DNPH (aldehydes), $\mathrm{C}_{1}, \mathrm{mmol} /(\mathrm{bhp} * \mathrm{~h})$} & \\
\cline { 3 - 5 } & $\begin{array}{l}\text { mmol/ } \\
(\mathrm{bhp} \text { h) }\end{array}$ & Formaldehyde & $\begin{array}{l}\text { Other } \\
\text { aldehydes }\end{array}$ & Total & $\begin{array}{l}\text { Formaldehyde (\% of } \\
\text { THC) }\end{array}$ \\
\hline HCCI (70 RON) & 758 & 403 & 38 & 441 & $53 \%$ \\
HCCI (87 RON) & 958 & 249 & 136 & 385 & $26 \%$ \\
PFS (70 RON) & 788 & 178 & 134 & 311 & $23 \%$ \\
HFS 1 (87 RON) & 151 & 42 & 18 & 60 & $28 \%$ \\
HFS 2 (87 RON) & 119 & 70 & 19 & 90 & $59 \%$ \\
HFS 1 (70 RON) & 157 & 80 & 30 & 110 & $51 \%$ \\
\hline
\end{tabular}

concentrations were converted to mass emission rates for comparison.

As described in Sect. 2.3, the customary practice in this laboratory and others has been to take two QFs for each EC/ OC measurement [15]. The primary QF collects PM and the secondary QF, in series downstream of the PTFE membrane filter, collects $\mathrm{HC}$ that absorbs to the quartz fiber matrix and not part of the PM. The OC measured on the secondary QF is subtracted from the primary QF to correct for this gas phase adsorption artifact. The assumption made in this correction is that the time it takes for the two QFs to come to equilibrium with the gas phase HCs in the exhaust stream is much faster relative to the sampling time. The stacked bar data in Fig. $6 \mathrm{a}$ was corrected for QF absorption artifacts as described. For comparison, the correction was not applied in Fig. 6b. There appears to be better agreement between the gravimetric PM mass rates, Fig. 6 (circles), and the TC mass rates calculated when no artifact correction was applied. A possible explanation for the discrepancy seen in Fig. 6 between the TC and gravimetric PM, when the artifact subtraction is done, is that the high level of HC has resulted in there being some hydrocarbon adsorption to the PM already deposited on the filter or on the PTFE membrane filter itself. This phenomenon has been observed by Maricq et al. in PM measurements of gasoline vehicles that have very low solid PM [22]. In previous research on more conventional spark-ignited combustion $[23,24]$, the correction has been applied with better agreement between TC and gravimetric PM. The discrepancy also points to potential problems with PM measurements during ACI operation. Just as ACI PM cannot be defined as soot carbon, the large amount of semi-volatile hydrocarbons present in ACI exhaust can lead to sampling artifacts such as filter adsorption. Future ACI PM research is needed to address these artifacts and how to avoid them.

Table 5 shows the OC, EC, TC, and gravimetric PM emissions for the different fuel-mode combinations. The results for the kinetically controlled modes (HCCI and PFS, Fig. 6) indicate similar PM mass emission rates for both 70 RON points. The 87 RON-HCCI point had about $50 \%$ more gravimetric PM than the 70 RON-HCCI point. This apparent fuel difference may be related to the higher THC emissions produced at the 87 RON-HCCI point compared to the 70 RONHCCI test condition (Table 3), in which the higher THC emissions may have led to "collection" of more hydrocarbon mass on the PM filter.

For the highly stratified modes (HFS), which are closely approaching stratification levels indicative of CDC, the 87 RON-HFS fuel points exhibited lower mass emissions than

Table 5 Filter-based total PM mass emissions and PM compositional distribution between organic (OC) and elemental (EC)

\begin{tabular}{|c|c|c|c|c|c|c|c|}
\hline & \multirow[t]{2}{*}{ Centroid of Inj $\left(^{\circ}\right)$} & \multirow[t]{2}{*}{ EGR $(\%)$} & \multirow[t]{2}{*}{ OC fraction $(\%)$} & \multicolumn{4}{|c|}{$\mathrm{mg} /(\mathrm{bhp} * \mathrm{~h})$} \\
\hline & & & & $O C$ & $E C$ & $T C^{a}$ & Gravimetric $P M^{\mathrm{b}}$ \\
\hline HCCI (70 RON) & 288 & 25 & 100 & 6.5 & 0.0 & 6.6 & 8.8 \\
\hline HCCI (87 RON) & 288 & 15 & 99 & 8.3 & 0.1 & 8.3 & 14.7 \\
\hline PFS (70 RON) & 262 & 25 & 96 & 6.7 & 0.3 & 6.9 & 9.3 \\
\hline HFS 1 (87 RON) & 17 & 15 & 97 & 6.2 & 0.2 & 6.4 & 10.0 \\
\hline HFS 2 (87 RON) & 15 & 15 & 71 & 4.2 & 1.8 & 6.0 & 9.3 \\
\hline HFS 1 (70 RON) & 13 & 25 & 76 & 3.1 & 1.0 & 4.1 & 5.8 \\
\hline HFS 2 (70 RON) & 11 & 15 & 33 & 4.9 & 10.0 & 14.9 & 16.3 \\
\hline HFS 3 (70 RON) & 10 & 0 & 24 & 7.0 & 22.4 & 29.4 & 33.3 \\
\hline
\end{tabular}

${ }^{\mathrm{a}}$ Total carbon mass rate was calculated $(\mathrm{TC}=\mathrm{OC}+\mathrm{EC})$ from the NIOSH method and included the artifact subtraction

${ }^{\mathrm{b}}$ PM mass rate was calculated from PM collected gravimetrically on the PM2.5 PTFE membrane filter 

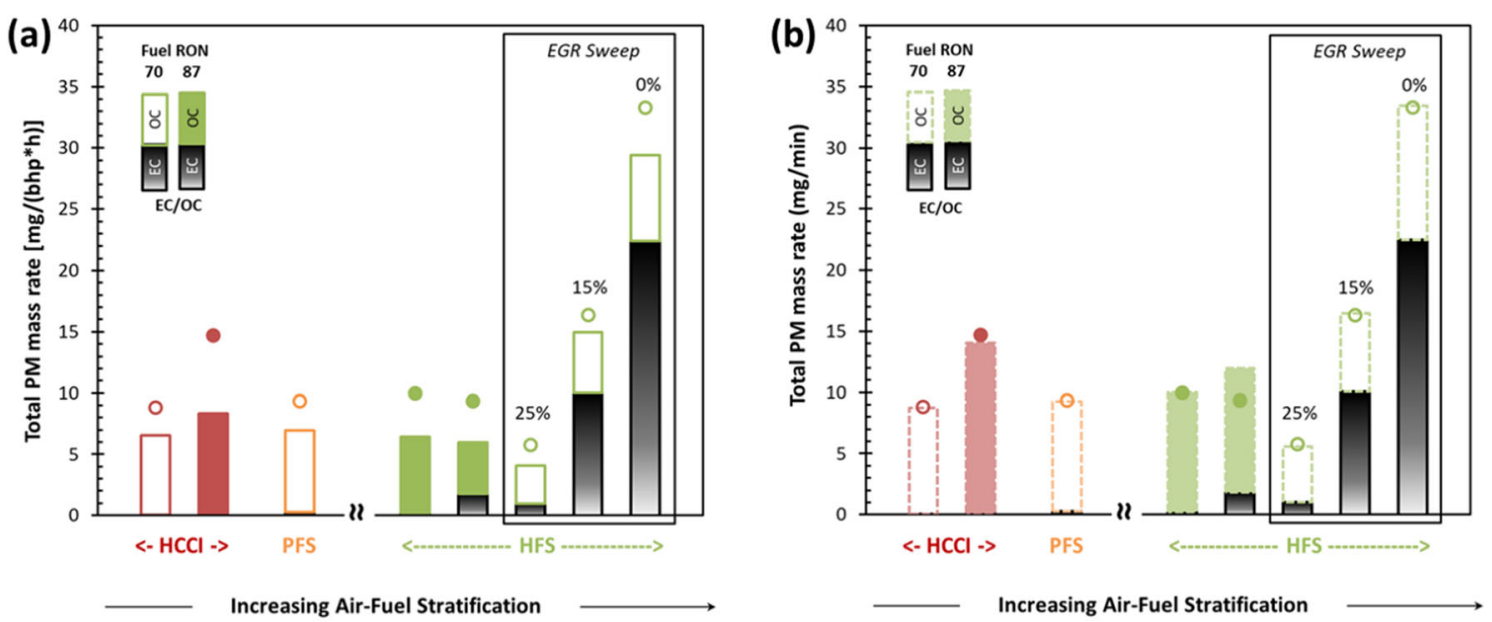

Fig. 6 PM mass emissions rate for the different fuels and combustion modes. The circle points are the gravimetric PM values and the bars are total C, with the EC and OC shown. A correction for gaseous OC artifact was applied in a but not in $\mathbf{b}$

the premixed 87 RON-HCCI point. The PM produced at the 87 RON-HFS 1 and -HFS two points were still predominately organic carbon with $97 \%$ and $71 \%$ OC, respectively (Table 5). This difference correlates with the lower THC emissions for the HFS points (Fig. 5b). Similarly, comparing the 70 RON kinetically controlled and HFS modes, the 70 RON-HFS 1 point had more EC (24\%, Table 5), but still lower overall PM emissions. The THC for the 70 RON-HFS 1 point was also much lower than the THC for the kinetically controlled modes (Fig. 5b).

For fuel-to-fuel comparison, the 70 RON-HFS point that correlates most closely, from a combustion standpoint, with the 87 RON-HFS points is the 70 RON-HFS 1, and it produced a lower PM mass rate. The same fuel differences discussed for the aldehyde emissions, fuel composition and reactivity, may also contribute to the higher PM mass rate measured for the 87 RON-HFS points. In gasoline, sparkignited combustion, higher aromatic content in the fuel, like the 87 RON, are associated with higher PM [25] emissions. Additionally, the higher reactive of the 70 RON fuel may lead to more complete combustion resulting in less PM with these ACI modes.

In order to achieve equivalent combustion phasing to the 87 RON-HFS points for the 70 RON-HFS 1 point, an increase in EGR (25\%) was required, compared to the two 87 RON-HFS points at 15\% EGR. Therefore, the effect of EGR on 70 RON-HFS PM was also investigated with an EGR sweep of $25 \%, 15 \%$, and $0 \%$. As a result of the change in EGR, the centroid of injection shifted slightly, Table 5. This shift in injection shows, as expected, that decreasing levels of EGR increased the level of air-fuel stratification and the total PM mass for the 70 RON EGR sweep. Figure 6 shows that the increase in PM emissions during the EGR sweep was due primarily to the increase in the EC, which reaches $76 \%$ of the total PM mass at the 0\% EGR point.

\subsection{MSS and EEPS Results}

As stated previously, the MSS is a photoacoustic measurement of the soot PM and thus can be compared to the EC portion of the PM compositional analysis. The plot in Fig. 7 shows a general agreement between the soot PM measured by the MSS and the EC measured by the NIOSH method, in terms of comparable magnitude between test points. However, the MSS consistently measures more mass than the EC fraction measured by the NIOSH method. One potential explanation for the elevated MSS reading is the presence of very small particles that respond to the photoacoustic detector but are too small to have significant mass. Additionally, if some of the organic carbon PM was incorporated into the particulate during the combustion stage, the OC may be located or incorporated into the core of a particulate rather than just on its surface as a result of adsorption or condensation. The MSS, ideal for measuring diesel particulate, which typically has a well carbonized structure and $<20 \%$ OC, measures the photoacoustic impact of the EC PM without being influenced by any OC that may have adsorbed or condensed on the diesel PM surface. In this instance, the photoacoustic signal may be skewed by OC with high degrees of conjugated bonds, like soot, or OC within a disordered EC or otherwise carbonized structure. While these results suggest that some of the $\mathrm{OC}$ fraction of the ACI PM is being measured by the MSS, it is still only a small fraction of the overall PM OC mass, as can be seen in Fig. 8, which compares the TC PM mass to that measured by the MSS.

The EEPS particle size distributions, shown in Figs. 9 and 10, further highlight the differences in ACI PM composition as a result of injection mode and fuel properties. The common delineation of particle size modes for emission particulate has been shaded in the EEPS figures as nuclei mode $(<25 \mathrm{~nm})$ and accumulation mode $(25-300 \mathrm{~nm})$ with all particles greater than 300 simply labeled larger agglomerates. The PMP 
Fig. 7 A comparison of soot PM measurements with the MSS and NIOSH (OC/EC) method for the eight engine points in this study. The dashed line is the $1: 1$ correlation. Solid circles indicate 87 RON points and open circles are 70 RON points; red (HCCI), orange (PFS), green (HFS)

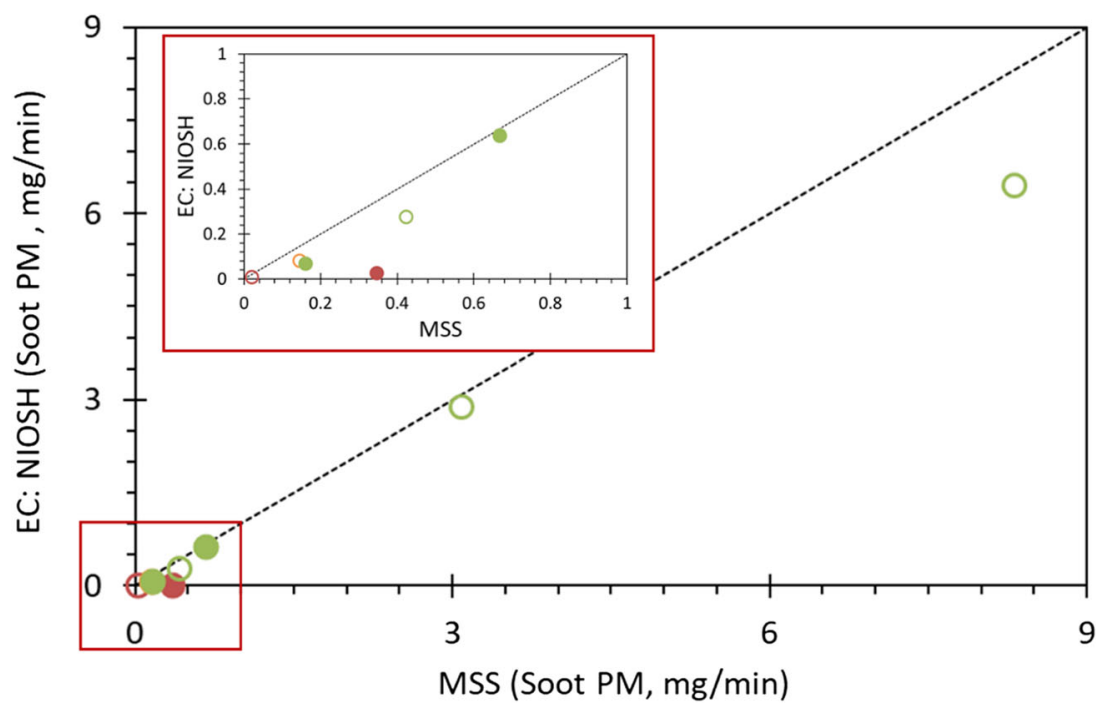

conditioning of the exhaust before EEPS sampling, briefly described in Sect. 2.3 [21], was developed for diesel PM emission measurements. The injection strategies, temperatures, and fuels of ACI combustion strategies, like those used in this study, are different than CDC, and therefore, may be expected to produce different types of particulates [11]. Therefore, the assumption that all nuclei mode particles, measured after the $350^{\circ} \mathrm{C}$ evaporation tube of the PMP, are solid EC particulate for diesel particulate may not hold true for ACI particulate. While detailed speciation of ACI PM was beyond the scope of this project, on-going work in our lab on ACI PM will include further investigation into the chemical difference which result from changes in injection mode and/or fuel properties.

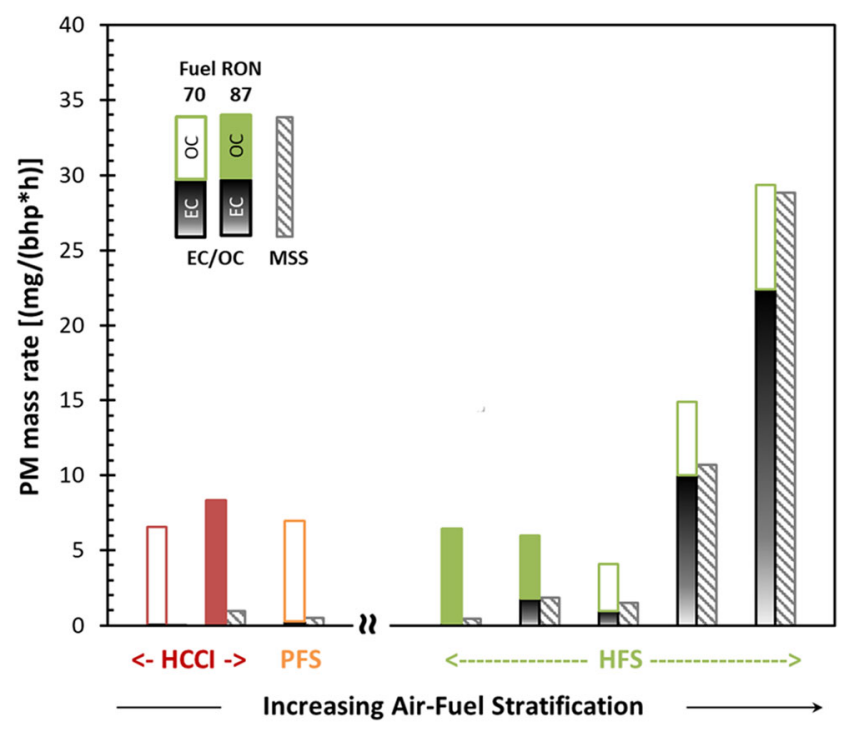

Fig. 8 PM mass emission rate for the different fuels and combustion modes. The stacked colored bars are from EC/OC measurements, with corrections for gaseous OC absorption, same data as Fig. 6a, while the hashed gray bars are from MSS measurements
In Fig. 9, the size distributions for the LTC modes (HCCI and PFS) for both fuels are shown as log plots (a) and semi-log plots (b). Since the PM composition for all three points was shown to be $>95 \%$ OC, and even $100 \%$ OC for the 70 RONHCCI point, it suggests that the particles measured by the EEPS would have to be largely organic carbon PM even in the nuclei mode region. The bimodal distribution for all three kinetically controlled conditions can clearly be seen in the log plot of Fig. 9a, with particles in both the nuclei and accumulation mode ranges. The Fig. $9 \mathrm{~b}$ semi-log plot shows a significant increase in nuclei mode particles was produced by the 87 RON fuel at the same, premixed, HCCI combustion mode compared to the 70 RON fuel. As the air-fuel stratification was increased from HCCI to PFS for the 70 RON fuel, an increase in both nuclei and accumulation mode PM particles was seen. The PM mass doubled when switching to the lower reactivity 87 RON fuel in the same HCCI mode (Fig. 6) even though an increase in particle number was only observed in the low mass nuclei mode range. Therefore, the difference in PM mass was likely from the organic portion of the PM mass that was volatilized by the PMP and not measured by the EEPS. In contrast, an increase in both nuclei and accumulation mode range particles resulted in little change in the total PM mass for the 70 RON fuel when the air-fuel stratification mode was changed from HCCI to PFS. Following the same logic, this suggests that even within the kinetically controlled combustion modes, the speciation of the organic portion of the PM may be impacted by changes in the fuel properties.

A comparison of the particle size distributions for the two 87 RON-HFS points and the 70 RON-HFS 1 point, which is most closely related to them (25\% EGR), is shown in the log plots (c) and semi-log plots (d) of Fig. 9. The point with the earliest centroid of injection of these three, 87 RON-HFS-1, clearly shows a bimodal distribution in the log plot, Fig. 9c, again indicating the presence of nuclei mode particles. All 
(a)

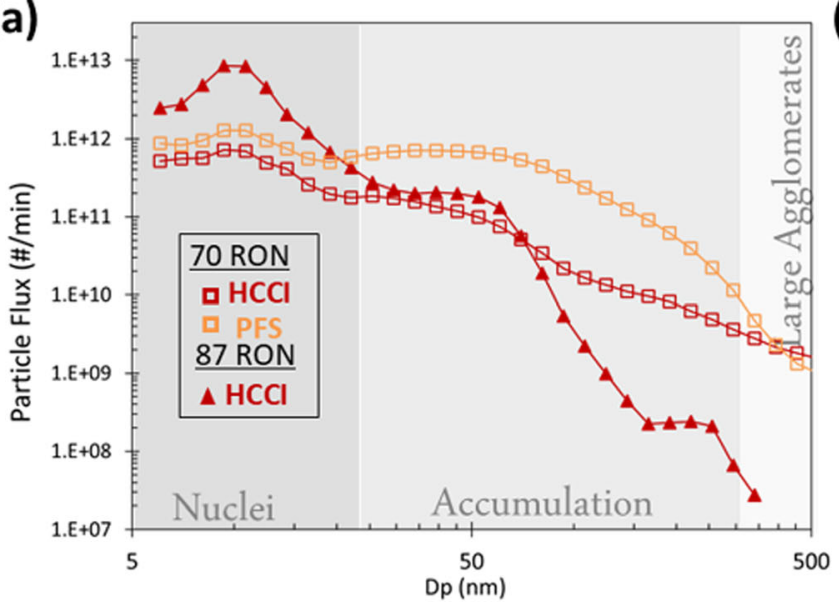

(c)

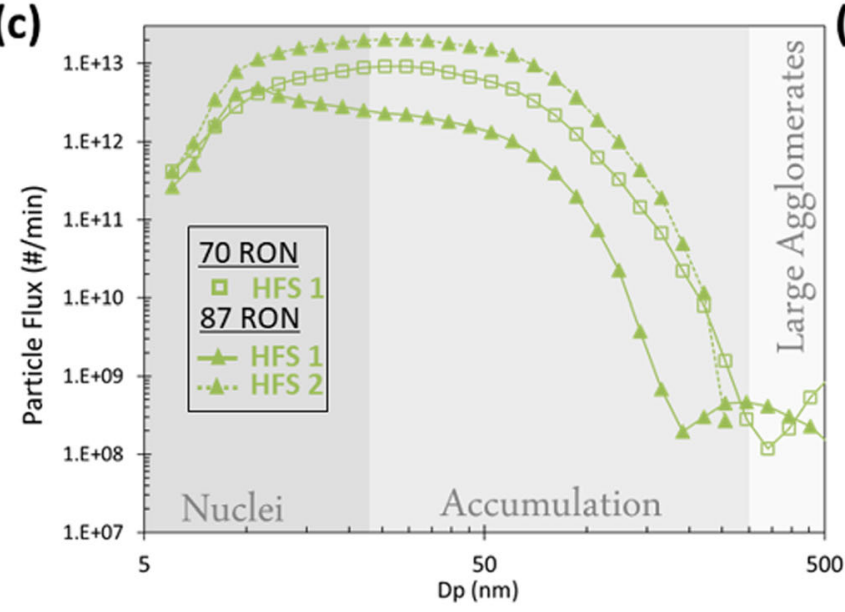

Fig. 9 A comparison of particle size distributions for the highly premixed cases $(\mathbf{a}, \mathbf{b})$ and HFS cases $(\mathbf{c}, \mathbf{d})$. The filled triangle symbols indicate 87 RON fuel and the open squares are 70 RON fuel. The semi-log plots (b,

three curves in (c) and (d) show a significant quantity of accumulation mode particles, consistent with the presence of soot PM indicated by the MSS and EC measurements.

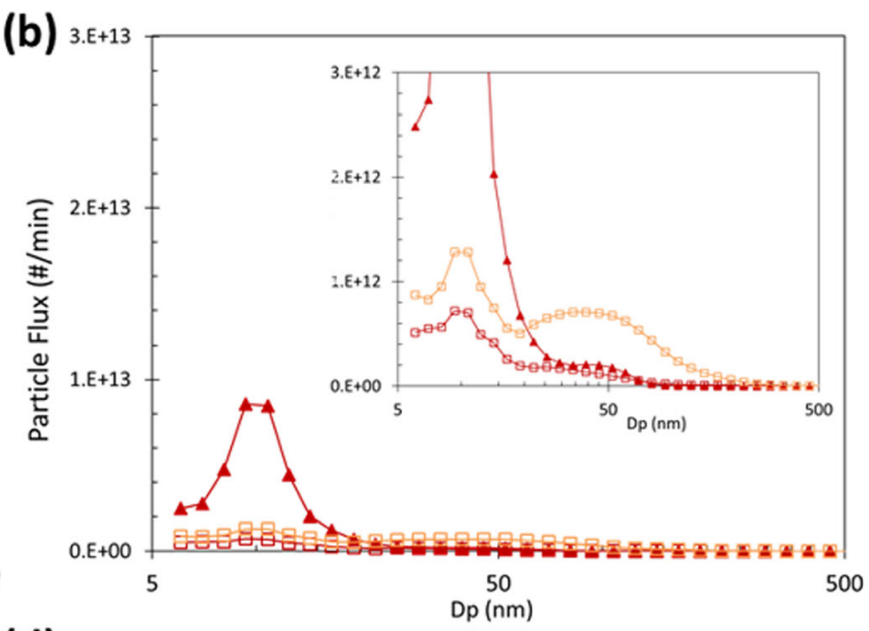

(d)

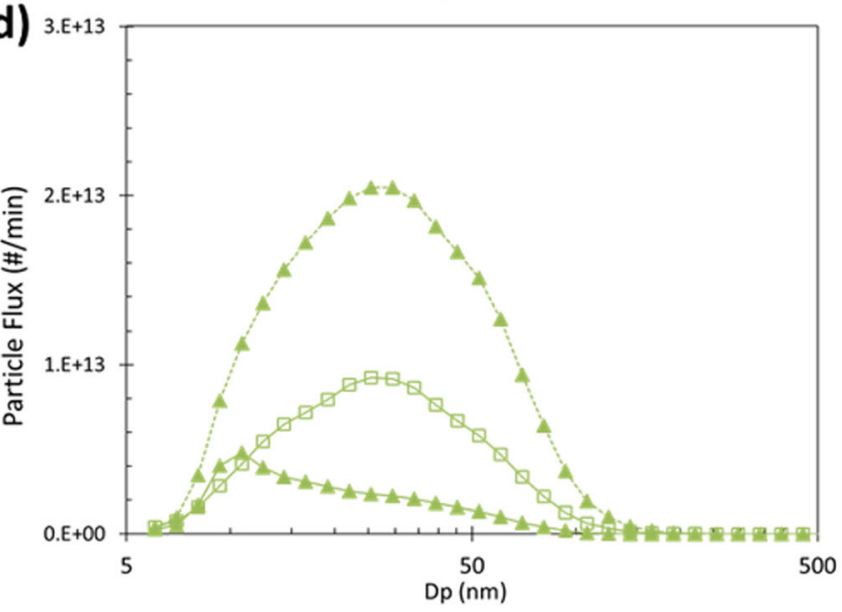

d) are shown to illustrate the bimodal nature of the distributions. The colors indicate the stratification mode: red-HCCI, orange-PFS, greenHFS

While a clear bimodal distribution was not seen for 87 RON-HFS-2 or 70 RON-HFS-1, all three contain more nuclei mode particles $(<25 \mathrm{~nm})$ than were observed for any of the (a)

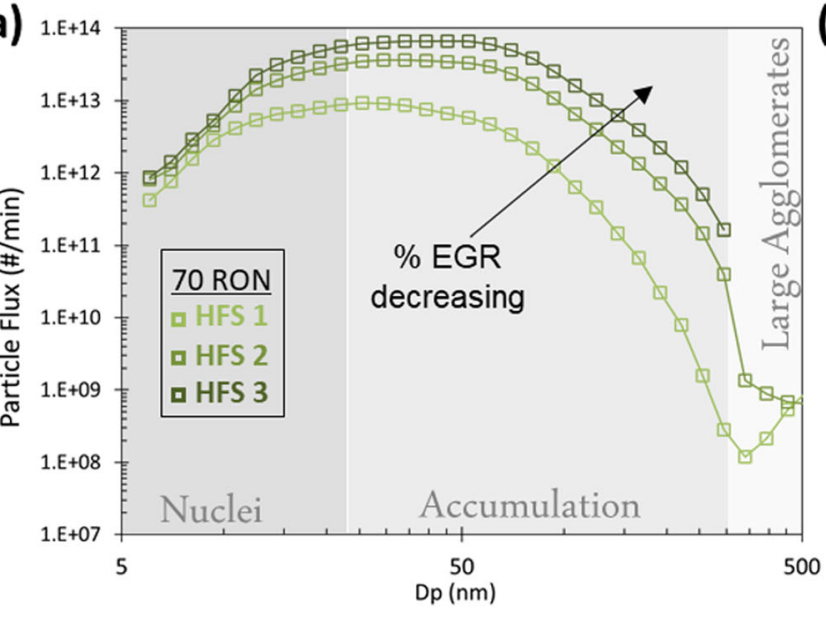

(b)

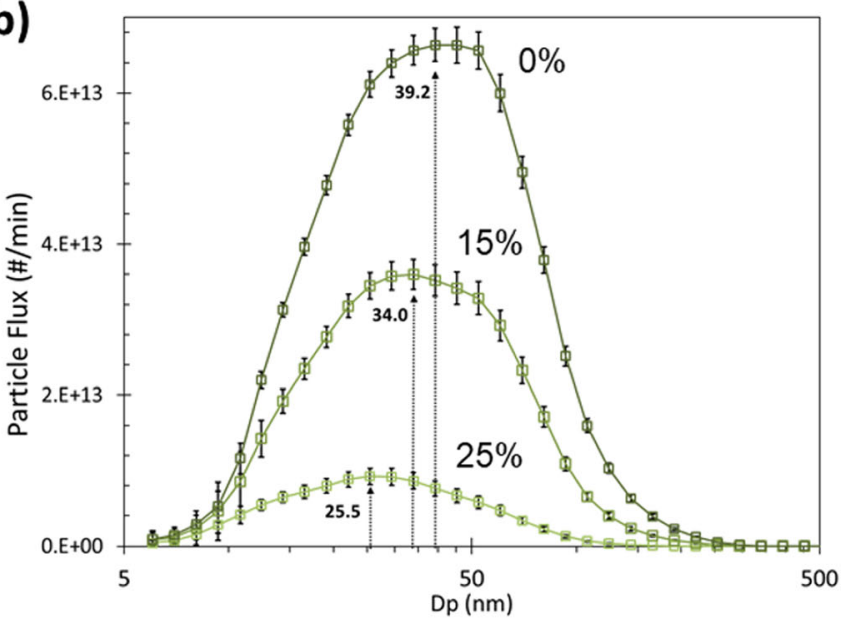

Fig. 10 A comparison of the particle size distributions for the 70 RON EGR sweep, points HFS1, HFS2, and HFS3. The mean particle size grows from $25.5 \mathrm{~nm}$ to $39.2 \mathrm{~nm}$ with decreasing EGR and increasing stratification, consistent with the increase in soot PM for these points 
kinetically controlled modes which show bimodal distribution in the Fig. 9 EEPS plots. The smaller amount of PM mass for the 70 RON-HFS-1 point shown in Fig. 6 appears at first to be inconsistent with the size distribution in Fig. 9c, d. The 87 RON-HFS 1 point has the smallest number of particles and smallest size distribution; however, it also has more large agglomerates (i.e., particles $>300 \mathrm{~nm}$ ) which tend to have more mass. This particular point also has low EC mass (Table 5), which implies that the large agglomerates likely make up a significant portion of OC mass. A future study using sizeselective speciation of the PM could determine the make-up of these larger particles.

In Fig. 10, the particle size distributions for the 70 RON EGR sweep (HFS-1, HFS-2, HFS-3) are shown. The increasing size of the mean particle diameter and amounts of particles in the accumulation mode correlate with the increase in soot PM and EC shown in Fig. 8. The mean diameter also increased from $25.5 \mathrm{~nm}$ to $39.2 \mathrm{~nm}$, Fig. 10, indicating particle growth in the accumulation mode.

The PM size distributions observed for the kinetically controlled HCCI and PFS points were similar to the ones observed for RCCI combustion with this engine [11]. In that study, the PM was also dominated by OC mass and in some cases EC mass was undetectable. Speciation of that RCCI PM found that the high boiling point components of the high reactivity fuel (ULSD or biodiesel) were the primary components of the OC. Both the 70 RON and 87 RON fuels are gasoline-range and do not have high boiling components like diesel, so the OC for these fuels may be composed of partially oxidized fuel species and other combustion products that have a lower volatility than the fuel HCs. Understanding the composition of the PM OC will be important to identifying PM control techniques for ACI operation, whether it is filterbased, oxidation catalyst based, or a combination of both.

\section{Summary/Conclusions}

This study was part of the overall Co-Optima initiative to develop fuel and engine technologies that will synergistically achieve significant efficiency gains. A current focus is on ACI combustion and optimal fuel properties. For any fuel-engine technology developed, a pathway for meeting regulated emissions must also be identified. Therefore, a main goal of this study was to understand the characteristics of the emissions formed during ACI combustion. Air-fuel stratification levels at either end of the ACI spectrum were investigated in this study to provide bookends to the PM formation phenomena. Gasoline-like fuels with two different RONs were used to capture fuel property effects. Overall emissions of NOx, under premixed, kinetically controlled combustion modes, were extremely low, but at the expense of high THC and CO emissions. As the air-fuel stratification was increased in the HFS modes, the soot PM fraction of the total PM emissions was seen to increase accounting for greater than $50 \%$ of the mass in the two most stratified modes. Measurements of the particle size distribution in these higher stratification modes illustrated the growth of the accumulation mode particles as the soot fraction increased. In most of the modes, however, the overall PM mass was dominated by OC. In many cases, a significant number of particles were measured suggesting that the $\mathrm{OC}$ was sufficiently non-volatile such that it survived a $350{ }^{\circ} \mathrm{C}$ evaporation tube prior to the particle sizing measurement.

The results of this study demonstrated how changes to fuel properties and engine strategies can impact PM and gaseous emissions. The following conclusions highlight some of these more specific findings reached:

- Aldehydes, indicative of partial oxidation processes during combustion, varied in amount and composition with fuel and stratification level. The aldehyde emissions were up to $\sim 60 \%$ of the THC emissions during ACI combustion. Emissions control strategies would be needed to address this level of aldehydes, in addition to the high THC and CO.

- Both fuel and air-fuel stratification mode impacted PM characteristics, influencing PM size and composition both in $\mathrm{EC} / \mathrm{OC}$ distribution and on the species within each of these fractions.

- These differences highlighted limitations of measurement techniques, designed for diesel emissions, for characterizing ACI PM. This further suggests that the formation pathway of ACI PM may not be the same as has been established for diesel PM.

Acknowledgements This research was conducted as part of the CoOptimization of Fuels \& Engines (Co-Optima) project sponsored by the US Department of Energy (DOE) Office of Energy Efficiency and Renewable Energy (EERE), Bioenergy Technologies and Vehicle Technologies Offices. (Optional): Co-Optima is a collaborative project of multiple national laboratories and universities initiated to simultaneously accelerate the introduction of affordable, scalable, and sustainable biofuels and high-efficiency, low-emission vehicle engines.

The authors would like to acknowledge the help from Vitaly Prikhodko and Steve Whitted for assistance with the experimental setup and running the FTIR as well as Jim Szybist and Martin Wissink for valuable input on the experimental plan and Scott Sluder for providing the fuel for the experiments.

Funding information Funding for this work was provided under Contract No. DE-AC05-00OR22725 with the US Department of Energy.

Open Access This article is distributed under the terms of the Creative Commons Attribution 4.0 International License (http:// creativecommons.org/licenses/by/4.0/), which permits unrestricted use, distribution, and reproduction in any medium, provided you give appropriate credit to the original author(s) and the source, provide a link to the Creative Commons license, and indicate if changes were made. 


\section{References}

1. US DOE Co-Optima Website https://www.energy.gov/eere/ bioenergy/co-optimization-fuels-engines. 11 Dec 2018

2. Dempsey, A.B., Curran, S., Wagner, R., Cannella, W.: Effect of premixed fuel preparation for partially premixed combustion with a low octane gasoline on a light-duty multicylinder compression ignition engine. ASME J. Eng. Gas Turbines Power. 137(11), 111506-111506-12 (2015). https://doi.org/10.1115/1.4030281

3. Kitamura, T., Ito, T., Senda, J., Fujimoto, H.: Mechanism of smokeless diesel combustion with oxygenated fuels based on the dependence of the equivalence ration and temperature on soot particle formation. Int. J. Eng. Res. 3(4), 223-248 (2002). https://doi.org/ $10.1243 / 146808702762230923$

4. Sellnau, M., Moore, W., Sinnamon, J., Hoyer, K., et al.: GDCI multi-cylinder engine for high fuel efficiency and low emissions. SAE Int. J. Engines. 8(2), 775-790 (2015). https://doi.org/10.4271/ 2015-01-0834

5. Sellnau, M., Foster, M., Moore, W., Sinnamon, J., et al.: Second generation GDCI multi-cylinder engine for high fuel efficiency and US tier 3 emissions. SAE Int. J. Engines. 9(2), 1002-1020 (2016). https://doi.org/10.4271/2016-01-0760

6. Ciatti, S., Johnson, M., Das Adhikary, B., Reitz, R., et al.: Efficiency and emissions performance of multizone stratified compression ignition using different octane fuels. In: SAE Technical Paper 2013-01-0263 (2013). https://doi.org/10.4271/2013-01-0263

7. Swanson, J.J., Franklin, L.M., Bika, A.S., Kittelson, D.B.: Size and volatility of particle emissions from an ethanol-fueled HCCI engine. Aerosol Sci. Technol. 51(5), 614-625 (2017). https://doi. org/10.1080/02786826.2017.1286289

8. Zelenyuk, A., Reitz, P., Stewart, M., Imre, D., Loeper, P., Adams, C., Andrie, M., Rothamer, D., Foster, D., Narayanaswamy, K., Najt, P., Solomon, A.: Detailed characterization of particulates emitted by pre-commercial single-cylinder gasoline compression ignition engine. Combust. Flame. 161(8), 2151-2164 (2014)

9. Zhang, Y.Z., Ghandhi, J., Rothamer, D.: Effects of fuel chemistry and spray properties on particulate size distributions from dual-fuel combustion strategies. SAE Int. J. Engines. 10(4), 1847-1858 (2017). https://doi.org/10.4271/2017-01-1005

10. Prikhodko, V.Y., Curran, S.J., Barone, T.L., Lewis, S.A., Storey, J.M., Cho, K., Wagner, R.M., Parks, J.E.: Emission characteristics of a diesel engine operating with in-cylinder gasoline and diesel fuel blending. SAE Int. J. Fuels. Lubr. 3(2), 946-955 (2010). https://doi. org/10.4271/2010-01-2266

11. Storey, J.M.E., Curran, S.J., Lewis, S.A., Dempsey, A., Barone, T.L., Moses-DeBusk, M., Hanson, R.M., Prikhodko, V.Y., Northrop, W.F.: Evolution and current understanding of physicochemical characterization of particulate matter from reactivity controlled compression ignition combustion on a multicylinder lightduty engine. Int. J. Eng. Res. 18(5-6), 505-519 (2017). https://doi. org/10.4271/2017-01-1005

12. Lucachick, G., Avenido, A., Kittelson, D., Northrop, W.: Exploration of semi-volatile particulate matter emissions from low temperature combustion in a light-duty diesel engine. SAE Int. J. Engines. 7(2), 852-859 (2014). https://doi.org/10.4271/ 2014-01-1306
13. Wissink, M.L., Curran, S.J., Roberts, G., Musculus, M.P., Mounaïm-Rousselle, C.: Isolating the effects of reactivity stratification in reactivity-controlled compression ignition with iso-octane and $n$-heptane on a light-duty multi-cylinder engine. Int. J. Eng. Res. 19(9), 907-926 (2018). https://doi.org/10.1177/ 1468087417732898

14. Birch, M.E., and Cary, R.A.: Elemental Carbon-Based Method for monitoring occupational exposures to particulate diesel exhaust. Aerosol Sci. Technol. 25(3), 221-241 (1996). https://doi.org/10. 1080/02786829608965393

15. May, A.A., Nguyen, N.T., Presto, A.A., Gordon, T.D., Lipsky, E.M., et al.: Gas- and particle-phase primary emissions from inuse, on-road gasoline and diesel vehicles. Atmos. Environ. 88, 247-260 (2014). https://doi.org/10.1016/j.atmosenv.2014.01.046

16. Lewis, S.A.: (to be published)

17. Giechaskiel, B., Dilara, P., Sandbach, E., Andersson, J.: Particle measurement programme (PMP) light-duty inter-laboratory exercise: comparison of different particle number measurement systems. Meas. Sci. Technol. 19(9), 5401 (2008). https://doi.org/10. 1088/0957-0233/19/9/095401

18. Sluder, C.S.: Estimation of the fuel efficiency potential of six gasoline blendstocks identified by the U.S. Department of Energy's Co-Optimization of Fuels and Engines Program, SAE Technical Paper 2019-01-0017 (2019). https://doi.org/10.4271/2019-01-0017

19. Shen, M., Lonn, S., Johansson, B. Transition from HCCI to PPC combustion by means of start of injection, SAE Technical Paper 2015-01-1790 (2015). https://doi.org/10.4271/2015-01-1790

20. Yang, B., Yao, M., Cheng, W.K., Zheng, Z., Yue, L.: Regulated and unregulated emissions from a compression ignition engine under low temperature combustion fueled with gasoline and n-butanol/ gasoline blends. Fuel. 120, 163-170 (2014). https://doi.org/10. 1016/j.fuel.2013.11.058

21. U.S. Code of Federal Regulations, 40 C.F.R 86.1811-17 - Exhaust Emissions Standards for Light-Duty Vehicles, Light-Duty Trucks and Medium-Duty Passenger Vehicles (2018)

22. Kayes, D., Hochgreb, S., Maricq, M., Podsiadlik, D., et al. Particulate matter emission during start-up and transient operation of a spark-ignition engine (2): effect of speed, load, and real-world driving cycles, SAE Technical Paper 2000-01-1083 (2000) https:// doi.org/10.4271/2000-01-1083

23. Storey, J., Barone, T., Thomas, J., Huff, S.: Exhaust particle characterization for lean and stoichiometric DI vehicles operating on ethanol-gasoline blends, SAE Technical Paper 2012-01-0437 (2012). https://doi.org/10.4271/2012-01-0437

24. Storey, J.M., Lewis, S., Szybist, J., Thomas, J., Barone, T., Eibl, M., Nafziger, E., Kaul, B.: Novel characterization of GDI engine exhaust for gasoline and mid-level gasoline-alcohol blends. SAE Int. J. Fuels. Lubr. 7(2), 571-579 (2014). https://doi.org/10.4271/201401-1606

25. Khalek, I., Bougher, T., Jetter, J.: Particle emissions from a 2009 gasoline direct injection engine using different commercially available fuels. SAE Int. J. Fuels. Lubr. 3(2), 623-637 (2010). https:// doi.org/10.4271/2010-01-2117

Publisher's Note Springer Nature remains neutral with regard to jurisdictional claims in published maps and institutional affiliations. 